\title{
Formulation of Green Varnish from Ecological Friendly Material for the Development of Offset Printing Ink
}

\author{
Zuhaili Idhama*, Mohd Azizi Che Yunusa, Mustafa Kamal Abdul Aziza, Siti Hamidah Mohd Setapara, Hasanah Mohamada \\ ${ }^{a}$ Centre of Lipid Engineering and Applied Research , Universiti Teknologi Malaysia, 81310 UTM Johor Bahru, Johor, Malaysia \\ *Corresponding author: zuhaili@cheme.utm.my
}

Article history

Received :1 October 2013

Received in revised form : 27 January 2014

Accepted :27 January 2014

\begin{abstract}
The extensive use of petroleum product has caused a number of environmental pollution. The printing industry is one of our nation's largest producers of hazardous waste and volatile organic compound. One of the major alternatives is to use vegetable oil based products as biorenewable raw materials. Hence, the formulation of palm olein based varnish has been discussed in the present study. Palm olein from palm oil was prepared first, and their physical properties were determined. Varnishes were prepared with the palm olein and four different types of resin (F-2136, F-210, F-2110 and F-2118). Rheological properties, yield value, heptanes tolerance of the varnish were determined. From this study, it was found that palm olein with the F-210 resin is promising as the alternative varnish materials for the production of offset printing ink.
\end{abstract}

Keywords: Varnish; palm olein; offset printing ink

\subsection{INTRODUCTION}

The awareness on the effects of petroleum products towards the environmental surroundings have urged for the development of alternative resource to replace the conventional petroleum to produce ink. The most suitable approach is green technology, using vegetable oil as the best alternative to replace petroleum-based ink, and to ensure the environment safe from contamination. The petroleum shortage in the 1970's also has stimulated research on vegetable-oil based inks as substitute for petroleum-based products [1].Vegetable ink has low level of volatile organic compounds (VOCs), thereby reduces air pollution by minimizing toxic emissions [2]. Other than that, vegetable oil inks, compared to petroleum-based inks, are less likely to build up on the printing plate, thus facilities can remain clean. This is because vegetable oil's boiling point is significantly higher than that of petroleum oil, and it is less likely to become volatile at high temperatures [3]. In addition, vegetable inks can reduce ink and paper waste because the balance between ink and water is easier to achieve [3].

There are some types of vegetable oil that have been identified possessing good quality of varnish, such as linseed oil, soybean oil, cottonseed oil and palm oil. Thus, the use of palm oil as vegetable oil materials in development of varnish and ink is one of the major alternatives to resolve the problem as the palm oil has an abundant source in Malaysia. Since vegetable oils are non-toxic, nonpollutant and biodegradable, they can be used as replacement for petroleum based products such as printing inks, adhesives and coating applications. This is because the vegetable oils contain higher percentage of desirable fatty acid and crops containing unique fatty acid.
There are two important stages in ink manufacture: firstly, varnish (a mixture of solvent, resins and additives) is made, and then pigments are mixed into it. Varnish is a clear liquid which is the base of any ink. Different varnishes are made for different inks, but they are all made from the mixture of resins, solvents and additives (often at high temperatures) to form homogeneous mixture [4,5]. The resins react together to some extent to become larger molecules, making the varnish more viscous[4]. Resins are primarily binders; they bind the other ingredients of the ink together so that they form a film, thus binding the ink to the paper. They also contribute to such properties as gloss and resistance to heat, chemicals and water [4]. In this present study, oleoresinous method was used in the preparation of varnish. In the production of typical oleoresinous ink varnish, drying oil, alkyd and other solvents are added into the vessel under nitrogen prior to cooking. Hard resins are then added when correct temperature is attained. The cooking process continues until the reactants are either totally consumed in the transesterification process or have achieved adequate solubility in the solvent. Additives such as the chelating agents are added after the batch cools down. Finally, the varnish mixture is reheated to obtain targeted rheological properties. The varnish produced is tested before sent to the storage tank [4].

The objective of this study is to prepare varnish from modified vegetable oil, i.e palm olein using different types of resin, for the production of the environmentally friendly ink. 


\subsection{MATERIALS AND METHOD}

\subsection{Materials}

Refined Bleached Deodorizated Palm Oil (RBDPO) was obtained from Nam Bee Company Sdn.Bhd (Palm Oil Mill). Methanol, Sodium Hydroxide Pellet $(\mathrm{NaOH})$, Al-Chelate, n-heptane, Toluene, Potassium hydroxide $(\mathrm{KOH})$ and Butylated hydroxytoluene (BHT) were purchased from Merck. Other materials such as Rosin-Modified Phenolic Resins (F-2136, F-210, F-2110 and F-2118), Polytetrafluoroethylene (PTFE) wax, Polyethylene (PE) wax, Black Pigment, Litho Paste and Mixed Dryer were purchased from Kras Instrument Sdn Bhd.

\subsection{Preparation of palm olein}

Three phases were involved: transesterification, phase separation and washing method. RBDPO was mixed with methanol in the presence of $\mathrm{KOH}$ as catalyst at $60^{\circ} \mathrm{C}$ for 30 minutes, and then put for 24 hours for phase separation. The completed reaction produced two different layers: the upper layer which was methyl ester product and the lower layer which was glycerin product. The produced methyl ester was palm olein.

\subsection{Characteristics of palm olein}

The produced palm olein was evaluated in terms of appearance, specific gravity, wax point, cloud point, and range of boiling point, as well as being compared with the standard mineral distillate. The cloud point of palm olein was determined by using laboratory standard method of ASTM D2500-91. Meanwhile, the specific gravity value was determined according to the ASTM D1298-85 method.

\subsection{Formulation of Varnishes}

The preparation of varnishes was slightly modified from Roy by varying $\mathrm{w} / \mathrm{w} \%$ formulation [6]. RBDPO was charged in a five necked one liter glass kettle fitted with a mechanical stirrer, a nitrogen inlet, a thermometer and a condenser. The preparation of varnish was begun by heating the resin at $150{ }^{\circ} \mathrm{C}$. The resin was heated continuously for 30 minutes. At $180^{\circ} \mathrm{C}$, palm olein (ester) was added and the mixture became gelled by addition of $0.5 \% \mathrm{Al}-$ cheleate at temperature of $160{ }^{\circ} \mathrm{C}$. Next, $0.5 \%$ of BHT was added and stirred for 5 minutes to allow the varnish to mix well. The varnish was cooled down to room temperature before proceeding to the next stage for manufacturing the offset printing ink. Same procedures were repeated for different types of resin

\subsection{Preparation of Ink}

Table 1 shows the list of ingredients for the formulation of offset printing ink [6]. Firstly, varnishes were mixed with palm olein in the stainless steel container and heated at $70{ }^{\circ} \mathrm{C}$. After that, the mixture was blended with $0.5 \%$ BHT and mixed with $18 \%$ Carbon Black (Elftex 8).

The temperature was increased to ensure all BHT dissolved. The resulting pigment was dispersed using a Rotary agitation, operated at $3000 \mathrm{rpm}$ to ensure the ink homogenized. After that, all remaining additives such as antisetoff paste, PTFE wax, PE wax, Litho paste and mixed dryer were put into the stainless steel container. The whole ingredients were mixed for 30 minutes. Lastly, the ink mixture was milled using the laboratory 3-roll mill to obtain fine size particle.
Table 1 Ink formulation

\begin{tabular}{lc}
\hline Raw Material & $\begin{array}{c}\mathbf{w} / \mathbf{w} \% \\
\text { formulation }\end{array}$ \\
\hline Varnish & 48 \\
Additive Varnish (Oil Based) & 20 \\
Black Pigment & 18 \\
Antiset Off Paste & 3 \\
PTFE Wax & 2 \\
PE Wax & 2 \\
Litho Paste & 1 \\
BHT & 0.5 \\
Mixed Drier & 1 \\
Palm Olein & 4.5 \\
Total & 100 \\
\hline
\end{tabular}

The temperature was increased to ensure all BHT dissolved. The resulting pigment was dispersed using a Rotary agitation, operated at $3000 \mathrm{rpm}$ to ensure the ink homogenized. After that, all remaining additives such as antisetoff paste, PTFE wax, PE wax, Litho paste and mixed dryer were put into the stainless steel container. The whole ingredients were mixed for 30 minutes. Lastly, the ink mixture was milled using the laboratory 3-roll mill to obtain fine size particle.

\subsection{Rheological Properties and Heptane Tolerance Analysis}

The viscosity and yield value of varnish and ink were measured based on dynamic viscosity using Brookfield Viscometer at $25^{\circ} \mathrm{C}$. For heptane tolerance analysis, $2 \mathrm{~g}$ of varnish was mixed with $2 \mathrm{~g}$ of toluene and the mixture was titrated with n-heptane at $25^{\circ} \mathrm{C}$ until the mixture became cloudy. The volume of n-heptane required was expressed as heptanes tolerance [7].

\subsection{RESULTS AND DISCUSSION}

\subsection{Characteristis of Ester Production}

Comparative properties of the mineral oil distillate and palm olein ester are presented in Table 2. The findings show that both ink vehicles were colourless. The wax point of ester is important to ensure the quality of printing ink production because it controls the cohesive, adhesion and ink flow [8]. It was also found that wax points of the palm olein esters were higher than that of mineral distillate which indicated the presence of saturated fatty acid in the vegetable esters. The higher quantity of wax present in mineral distillate or in vegetable ester will decrease flowability, especially at low ambient temperature. With low flowability of ink, the performance of offset printing ink on the machine will be disrupted and result in poor quality image.

Table 2 The properties of mineral distillate and vegetable oil ester

\begin{tabular}{lcc}
\hline Properties & Palm Olein Ester & Mineral Distillate \\
\hline Appearance & Colourless & Colourless \\
Liquid & Liquid \\
Specific Gravity & $0.8735 \pm 0.005$ & $0.8550 \pm 0.005$ \\
Wax Point & $19 \pm 1$ & $-2 \pm 0.5$ \\
Cloud Point & $13 \pm 0.5$ & -- \\
Boiling Point & $310 \pm 4$ & $280 \pm 4$ \\
& &
\end{tabular}




\subsection{Effect of Different Types of Resin on Viscosities and Heptane Tolerance}

The varnish produced from different types of rosin modified phenolic resin which are F-2136, F-210, F-2110 and F-2118. The Rosin Modified Phenolic resin is yellow or brownish translucent solid, reacted from gum rosin and alcohol with the matters polycondensation by different phenolic and aldehydes. These four types of resin have different characteristics and applications as shown in Table 3 due to different degree of reaction. Type F-2136 rosin modified phenolic resin has good oil solubility, solvent solubility and water resistance. However, this type of resin does not have high viscosity. The F-2136 resin is suitable to use as lacquer, adhesive, printing ink, natural resin varnish and all purpose adhesive. The F-210 resin has a high softening point, high viscosity and brightness. Type F-2110 resin has light color, good oil solubility and water resistance. Usually, this type of resin is used as lacquer, printing ink, all-purpose adhesive and electric material bonding agent. Lastly, type F-2118 resin has high softening, good oil solubility, good brightness and fast fastening [9].

Table 3 Characteristic of resins [9]

\begin{tabular}{|c|c|}
\hline Type of Resin & Characteristics \\
\hline F- 210 & $\begin{array}{l}\text { Good oil solubility, solvent } \\
\text { solubility and water resistance. }\end{array}$ \\
\hline F-2110 & $\begin{array}{l}\text { Light color, good oil solubility, } \\
\text { solvent solubility and water } \\
\text { resistance. }\end{array}$ \\
\hline F-2118 & $\begin{array}{l}\text { High softening point, good oil } \\
\text { solubility, good brightness, fast } \\
\text { fastening. }\end{array}$ \\
\hline F-2136 & $\begin{array}{l}\text { High softening point, viscosity and } \\
\text { brightness. }\end{array}$ \\
\hline
\end{tabular}

Table 4 shows the obtained properties of varnish when using different types of resin. Heptane tolerance is an important factor to evaluate the printing properties of finish ink ${ }^{7}$. The value of heptanes tolerance for varnish with F-210 was found higher compared to the other varnish. This implies that the compatibility of the resin type F-210 in the varnish is much better compared to other types of resin, since the heptane tolerance value increased with the increase of the degree of reaction. The degree of reaction is generally related to the viscosity and the type of resin used. Therefore, using varnish with high viscosity will increase the heptanes tolerance value and produce ink with better gloss.

Table 4 The properties of varnish based on four different types of rosin

\begin{tabular}{lllll}
\hline Properties & Resin 2136 & Resin 210 & Resin 2110 & Resin 2118 \\
\hline $\begin{array}{l}\text { Heptane } \\
\text { Tolerance,ml }\end{array}$ & 10.3 & 12.4 & 6.1 & 7.86 \\
$\begin{array}{l}\text { Viscosity, cp } \\
\begin{array}{l}\text { Yield Value, } \\
\text { dynes/cm }\end{array}\end{array}$ & 11.0 & 32.6 & 10.6 & 13.9 \\
\hline
\end{tabular}

It is found that, high flowabilities and high viscosities of offset inks, are required to improve the quality of printed articles [10]. The highest viscosity was achieved by varnish from resin type F210. Meanwhile, varnish produced using F-2110 resin showed the lowest viscosity value among others. Viscosity of varnish with $\mathrm{F}$ -
2136 and F-2118 resins were 10.3 centipoise and 7.86 centipoise, respectively.

The result was similar to the yield value of varnish. Varnish from F-210 resin had high yield value, signifying that the ink would have a proper structure to withstand the shear force generated between machine ink rollers during printing. If using low yield value of varnish, the structure could break easily and it would be difficult to get proper ink transfer, which could affect the printing quality. Therefore, from the results of this study, it can be concluded that F-210 resin is the most suitable resin to be used as a binding agent for preparation of varnish before manufacturing the offset printing ink.

\subsection{Rheological Properties of Offset Printing Ink}

Based on the results as shown in Table 5, Ink A had higher viscosity compared to Ink B. This is because, the mineral distillate had a large molecular weight compared to palm olein ester. Generally, the difference among oils in apparent molecular weight suggests a decrease in the particle size of ink. When the size of particle decreases, the attraction between particles will lose and this easily breaks the bond. This mechanism will cause the ink production to dilute and not viscous [10]. For the yield value, the Ink B was supposed to have lower yield to Ink A. This happened due to different types of solvents (mineral distillate and palm olein). The yield values, obtained as the result, were related to their viscosities. If the viscosity of an ink is low, it will produce low yield value. A good combination of rheology properties in the printing ink will produce clear and sharp print images with good dot reproduction [10]. According to Kipphan, for offset printing ink, highly viscous pasty ink are necessary between 40-100 Pa.s (40,000-100,000 centipoise) [11]. Thus, eventhough the rheology properties of Ink $\mathrm{B}$, which was based on palm olein ester had less viscosity, it is still in the range of suitable viscosity value for the offset printing ink.

Table 5 Rheological properties of mineral ink and palm ink

\begin{tabular}{lll}
\hline Properties & $\begin{array}{l}\text { Ink A } \\
\text { (Based on } \\
\text { mineral } \\
\text { distillate) }\end{array}$ & $\begin{array}{l}\text { Ink B } \\
\text { (Based on } \\
\text { Palm Ester) }\end{array}$ \\
\hline $\begin{array}{l}\text { Molecular weight of } \\
\text { solvent(g) }\end{array}$ & $480-500$ & 282.31 \\
$\begin{array}{l}\text { Viscosity (Centipoises) } \\
\text { Yield Value (Dynes/cm }{ }^{2} \text { ) }\end{array}$ & 175000 & 75400 \\
\hline
\end{tabular}

\subsection{CONCLUSION}

Type of resin has large influence on viscosity, heptanes tolerances and yield value of varnish. The result showed that the viscosity of varnish based on Resin F-210 was the highest among other samples. It can be concluded that, varnish based on resin 210 is more efficient and effective to use for ink manufacturing because it fulfills the requirement to make ink varnish. Overall, palm olein ester is indeed suitable to replace petroleum distillate because it is environmental friendly and still in the range of suitable viscosity for the offset printing ink production.

\section{Acknowledgement}

The authors would like to thank for the cooperation and lab facilities from Centre of Lipid Engineering and Applied Research, Universiti Teknologi Malaysia (UTM) and gratefully appreciated the financial support from Research University Grant Scheme 
UTM (Vot No: Q.J130000.7125.01J83) from Minister of Higher Education, Malaysia.

\section{References}

[1] Erhan, S. Z. and M. O. Bagby. 1995. Vegetable-oil-based Printing Ink Formulation and Degradation. Industrial Crops and Products. 3: 237-246

[2] MacFadden, T., M. P. Vogel and E. D. 1996. Printing Ink. Printer National Environmental Centre.

[3] Dharavath, H. N. and K. Hahn. 2009. Green Printing: Colorimetric and Densitometric Analysis of Solvent-based and Vegetable Oil-based Inks of Multicolor Offset Printing. The Journal of Technology Studies. 35(2): 3646.

[4] Wansbrough, H. Printing Ink Technology and Manufacture, X-Polymers$\begin{array}{llll}\text { E-Printing inks. } & 1-13 \text {. From } \quad \mathrm{http} / / \mathrm{reg}\end{array}$ nzic.org.nz/ChemProcesses/polymers/10E.pdf.
[5] Whitehead, H. C. C. 2000. Modern Techniques in the Manufacture of Printing Inks. Surface Coalings International. 5: 240-242

[6] Roy, A. S., M. Bhattacharjee, R. Monal and S. Ghosh. 2007. Development of Mineral Oil Free Offset Printing Ink Using Vegetable Oil Esters. J. Oleo Sci. 56(12): 623-628.

[7] Bhattacharjee, M., A. S. Roy, S. Ghosh, and M. Dey. 2011. Development of Karanja Oil Based Offset Printing Ink in Comparison with Linseed Oil. J.Oleo Sci. 60(1): 19-24.

[8] Tabbernor, G. A. 1993. Rheology of printing ink. In Printing Ink Manual (R.H Lynch: R. Pierce. ed). 5th edn. Blue Print, an Imprint of Chapman and Hall. London. 766-803.

[9] Ninghua Lifeng Chemical Co. 2011. Rosin Modified Phenolic Resin from: http://www.lifengchem.com/pages/p15e.

[10] Yamaguchi, H., S. Shinozaki, T. Suzuki and M. Aritomi. 2010. Rheology and Printability of Offset Inks. Article Report for DNP Fine Chemicals Co. Ltd.

[11] Kipphan, H. 2001. Handbook of Print Media: Technologies and Production Methods. 137-138. 